\title{
O TRABALHO DO PEDAGOGO NOS INSTITUTOS FEDERAIS DE EDUCAÇÃO CIÊNCIA E TECNOLOGIA: ALGUMAS ANÁLISES
}

\author{
C. R. S. Carrijo'; ' S. P. C. Cruz ${ }^{2}$ e K. A. C. P. C. da Silva ${ }^{3}$
}

E-mail: crsouza.pedagogia@gmail.com ${ }^{1}$; shirleidesc@gmail.com ${ }^{2}$; ${\text { katiacurado@unb.br }{ }^{3}}^{3}$

Universidade de Brasília

Artigo submetido em maio/2015 e aceito em junho/2016

DOI: 10.15628/rbept.2016.3487

\section{RESUMO}

O texto trata da análise de como se dá o trabalho do pedagogo nos Institutos Federais de Ensino Ciencia e Tecnologia (IFs), Nesse sentido, partiu da seguinte questão de pesquisa: Como se apresenta o trabalho do pedagogo na educação profissional técnica e tecnológica dos Institutos Federais? Realizou-se por meio do levantamento de publicações de artigos sobre a atuação do pedagogo nos IFs em revistas dos próprios institutos entre o ano de criação dos institutos, 2008, até 2014 para uma análise do cenário de atuação desse profissional. Os resultados dessa análise apontaram que existe uma atuação do pedagogo técnico ligada aos processos de supervisão, gestão e administração escolar, exigindo do pedagogo a mobilização de amplos saberes que dão visão da totalidade educacional, envolvendo os conhecimentos didático-pedagógicos, administrativos e legais da educação.

PALAVRAS-CHAVE: Educação Profissional, Pedagogo, Demandas profissionais.

\section{THE PEDAGOGUE WORK IN FEDERAL INSTITUTES OF SCIENCE AND TECHNOLOGY EDUCATION : SOME ANALYSES}

\section{ABSTRACT}

The text deals with the analysis of how is the work of the pedagogue in the Federal Institutes of Science Education and Technology (IFs), In this sense, came from the following research question : How presents the work of the pedagogue in professional technical and technological education of Institutes Feds? Held by the lifting of articles published about the role of the pedagogue in IFs in magazines own institutes between the year of establishment of the institutes, in 2008 , by
2014 for an analysis of this professional performance scenario. The results of this analysis showed that there is a role of technical pedagogue linked to supervisory processes, school management and administration, requiring the pedagogue to mobilize broad knowledge that give vision of educational entirety, involving the didactic and pedagogical knowledge, administrative and legal education

KEYWORDS: Professional Education, Pedagogue, Professional demands. 


\section{INTRODUÇÃO}

Esse trabalho teve como principal objetivo analisar o trabalho do pedagogo técnico na educação profissional técnica e tecnológica dos Institutos Federais de Educação, Ciência e Tecnologia com a seguinte questão de pesquisa: Como se apresenta o trabalho do pedagogo na educação profissional técnica e tecnológica dos Institutos Federais? Como objetivos específicos, realizamos um levantamento de estudos sobre o pedagogo na educação profissional, analisamos a base legal que subsidia a entrada do pedagogo na educação profissional e, por fim, analisamos o cenário de atuação do pedagogo nos Institutos Federais a partir de artigos publicados sobre a temática nas revistas dos próprios institutos.

Para efeito deste texto trazemos dados do levantamento de publicações de artigos sobre a atuação do pedagogo nos IFs em revistas dos próprios institutos entre o ano de criação dos institutos, 2008, até 2014 para uma análise do cenário de atuação desse profissional, tendo como referencial teórico os estudos da atuação do pedagogo no espaço escolar e extraescolar analisando o papel técnico e docente desse profissional.

\section{DIFERENÇAS E PROXIMIDADES ENTRE PAPEL TÉCNICO E PAPEL DOCENTE: A ATUAÇÃO O PEDAGOGO EM DIFERENTES ESPAÇOS}

O que, primeiramente, delimita a atuação da pedagogia é a intencionalidade educativa. Segundo Libâneo (2010) o pedagogo irá se ocupar de uma educação intencional e ressalta que nem sempre a atividade pedagógica é uma prática docente. $O$ autor também coloca que:

pedagogo é o profissional que atua em várias instâncias da prática educativa, direta ou indiretamente ligadas à organização e aos processos de transmissão e assimilação dos saberes e modos de ação, tendo em vista objetivos de formação humana previamente definidos em sua contextualização histórica.(Libâneo, 2010, p. 33).

Considerando a amplitude do trabalho pedagógico, os espaços de atuação se dividem basicamente nos espaços escolares e nos espaços extraescolares. No campo escolar o pedagogo pode atuar no espaço privado ou público como docente, supervisor, gestor, administrador, orientador educacional, em atividades paraescolares, dentre outros. No campo extraescolar o pedagogo pode trabalhar no setor público ou privado com atividades pedagógicas como as de formação, promoções sociais, capacitação, orientação de estagiários, dentre outros.

As mudanças sociais também pedem mudanças educacionais. Quando surgem novas demandas na sociedade, a exemplo das mudanças do mercado de trabalho com a modernização, também surgem necessidades educacionais diferentes que não necessariamente serão totalmente supridas pelas escolas. Outros espaços educativos surgem e/ou se transformam para atender a essas novas demandas

Outra forma de conceituar os amplos campos de atuação do pedagogo são os campos de educação formal ou educação não-formal. "Muitos autores trabalharam apenas com o dualismo: formal ou informal." (Gohn, 2010, p. 15) Porém, a autora diz que há uma diferença grande sobre 
o conceito de informal e não-formal. Nessa perspectiva, temos três conceitos diferentes de espaços educativos: formal, não-formal e informal.

A escola é a instituição em que a educação formal é mais expressiva, pois, os processos escolares necessitam de formalidade em seus processos organizacionais. Toda escola possui uma estrutura, ou seja, uma forma, no que implica a palavra formal. Contudo, a educação formal pode ocorrer em outros espaços em que seja necessário o ensino. Segundo Libâneo (2010, p. 88) "Educação formal seria, pois, aquela estruturada, organizada, planejada intencionalmente, sistemática".

Já a educação não-formal "é aquela que se aprende "no mundo da vida", via os processos de compartilhamento de experiências, principalmente em espaços de ações coletivas cotidianas" (Gohn, 2010, p.16). A educação não-formal não provém da relação espontânea com o mundo e, mesmo assim, não precisa estar ligada à escola para acontecer com intencionalidade pedagógica.

A educação escolar e extraescolar, formal e não-formal tem conceitos bem distintos, como já descrito anteriormente, porém, todas elas podem se encontrar em um mesmo ambiente de educação. Essas diferentes maneiras de educação constituem práticas profissionais diferentes, essencialmente para o pedagogo.

O pedagogo, sendo o profissional que atua na área da educação intencional, poderá estar presente tanto no espaço de educação escolar e extraescolar, atuando na educação formal ou não formal, ora separadamente, ora concomitantemente. A formação de pedagogo, como é definida nas diretrizes curriculares, coloca claramente que as questões técnicas de gestão, supervisão, organização institucional e outros, também fazem parte das habilidades docentes desejáveis.

Dessa forma, o pedagogo poderá atuar no ambiente escolar de educação formal, porém, ele pode ter como trabalho desenvolver a educação sendo docente professor, ou ter como trabalho desenvolver a educação de maneira "não-formal" com atividades técnicas, ou ser um docente que irá atuar concomitantemente na perspectiva técnica, ou ainda, ser um técnico que em algum momento atuará na perspectiva docente, na formação de profissionais por exemplo.

Nessa perspectiva, muitas vezes o pedagogo pode aparecer no ambiente escolar como gestor. Isso implicará ao pedagogo em mais responsabilidades sobre todos os modos de processos educativos. $O$ pedagogo gestor deverá mobilizar saberes relacionados a várias áreas educacionais, assim como propõem as DCNs, que o pedagogo tenha formação em gestão, avaliação, acompanhamento, docência, execução e elaboração de projetos.

Pimenta (2004), ao definir os saberes docentes, os divide em três grupos: o da experiência (constituído pela atuação profissional na iteração com docentes e discentes), o do conhecimento ou científico (sobre as áreas específicas do conhecimento) e os dos saberes pedagógicos, (advindos da formação, sobre educação e pedagogia) e, segundo ela, a Pedagogia é "ciência que tem a prática social da educação como objeto de investigação e de exercício profissional - no qual se inclui a docência, embora neles se incluam outras atividades de educar". (Pimenta, 2011 apud Pinto 2011, p. 13)

$\mathrm{Na}$ escola não existe espaço somente para o pedagogo professor, mas também, para o pedagogo escolar que terá um grande campo de atuação com muita importância nos processos 
educativos. O trabalho do pedagogo escolar terá influência no trabalho dos demais profissionais da escola, principalmente na dos professores.

A docência requer conhecimento sobre os processos de aprendizagem e, para o pedagogo é mais do que isso. O pedagogo precisará conhecer e compreender sobre os processos educativos, de forma mais abrangente. Os pedagogos podem ter demandas complexas que requerem conhecimentos e habilidades especializados.

\footnotetext{
A atuação do pedagogo escolar é imprescindível na ajuda aos professores no aprimoramento do seu desempenho na sala de aula (conteúdos, métodos, técnicas, formas de organização de classe), na análise e compreensão das situações de ensino com base nos conhecimentos teóricos, ou seja, na vinculação entre as áreas do conhecimento pedagógico e o trabalho de sala de aula. (LIBÂNEO, 2010, p. 61)
}

Há atividades que requerem esse conhecimento amplo em que, por muitas vezes, é espaço de atuação do pedagogo e que se extrapola o âmbito do conhecimento científico. Como exemplo, a função de Coordenação Pedagógica, Orientação Educacional e cargos de gestão que ampliam o conhecimento educacional também ao âmbito administrativo. Esse pedagogo terá que desenvolver seu trabalho unindo os conhecimentos pedagógicos amplos e os de sala de aula e, embora não necessite ter domínio total do conteúdo de cada disciplina ministrada, não deverá perder de vista o processo "educativo-docente". Segundo Libâneo (2010, p. 62) o trabalho do pedagogo deve ocorrer "operando uma interseção entre a teoria pedagógica e os conteúdosmétodos de cada matéria de ensino, entre o conhecimento pedagógico e o de sala de aula.".

O pedagogo, sobretudo o que atua fora ou para além de sala de aula no ambiente escolar, precisa mobilizar saberes para além dos conhecimentos metodológicos e científicos da docência. Isso não quer dizer que os saberes docentes podem ser deixados de lado. É importante ressaltar que na escola o principal objetivo ou o objetivo fim é a efetivação da aprendizagem, principalmente o da sala de aula. Por isso é importante que os amplos conhecimentos trabalhem com a docência e a favor dela.

(...) o trabalho de acompanhamento, assessoramento, coordenação e viabilização das atividades docentes e discentes no interior das escolas dever ser desenvolvido por profissionais com sólida formação pedagógica que supere as expectativas cristalizadas pelo cotidiano escolar. (PINTO, 2011, p. 24).

Fica claro o quão amplo é a área de atuação do pedagogo e de quantas competências esse profissional pode precisar dispor para o seu trabalho. Segundo Melo (2012, p. 03) “A pedagogia se propõe a formar humanos, a fim de adquiriram características humanas necessárias para a vida em sociedade, diante de uma realidade sempre de mudança." A formação humana pode ocorrer em qualquer circunstância, o que amplia ainda mais o campo de atuação do pedagogo na escola e também fora dela.

Para Melo (2012) "A Mobilização dos saberes acontece para atender as necessidades do trabalho pedagógico, e está relacionada ao domínio dos conhecimentos adquiridos pelo Pedagogo já ressignificados pelo e no trabalho pedagógico no momento de sua realização..." (p. 05). 
Isso pode também se aplicar à prática do pedagogo escolar, principalmente o que atuará em cargos de chefia e gestão. Esse profissional deverá, como ideal, agregar os amplos conhecimentos pedagógicos. Embora o objetivo fim da educação formal escolar seja a promoção da aprendizagem dos alunos, existem vários fatores anteriores a esse que englobam outros processos de aprendizagem em funcionários/ servidores, sejam docentes ou não. Anterior, após e simultaneamente à sala de aula, outros processos pedagógicos acontecem a fim de concretizar todo o processo educativo, fazendo com que a escola deva funcionar como engrenagem, em parte semelhante à lógica de empresas.

No ambiente de educação escolar formal, a atuação do pedagogo em prol da aprendizagem não somente poderá ocorrer direcionada aos alunos, mas também, a toda a equipe e comunidade escolar, incluindo docentes, técnicos e familiares na intencionalidade no seu trabalho. Todos os partícipes do ambiente escolar se tornam educadores e partes construtoras do conhecimento. Isso faz com que todos precisem estar em constante processo de aprendizagem para promover aprendizagem. Para tanto é necessário que estejam preparados para lidar com a realidade educacional, que está sempre em transformação.

\section{O PEDAGOgo E OS INSTITUTOS FEDERAIS DE EDUCAÇÃO, CIÊNCIA E TECNOLOGIA: ALGUMAS ANÁLISES}

Por meio de pesquisas feitas nas revistas publicadas pelos institutos em todos os estados brasileiros com busca em todas as edições de cada revista encontrada, foi possível ter informações que auxiliam no delineamento da identidade e do conhecimento sobre o seu trabalho, atribuições e desafios nos IFs. Algumas revistas existem antes da criação dos Institutos, pois, eram das antigas CEFETs e foram incorporadas aos IFs. Para a realização da pesquisa, foram considerados os artigos publicados desde a criação dos Institutos Federais, compreendendo, então, o período de 2008 a 2014. As revistas encontradas foram: EDUCTE, Igapó, Pindorama, Conexões, Debates em Educação Científica e Tecnologia, Sala de Aula em Foco, Revista IFES Ciência, Eixo, CETS, ACTA, Proficiência, For Science, Engrenagem, Principia, Cientec, Somma, Ciências e Ideias, Vértices, Holos, Ligar, REDI, Norte Científico, Técnico-Científica, Sinergia, Caminhos da Educação Matemática em Revista, Jornada de Iniciação Científica e Extensão. Desse universo, totalizando pouco mais de mil e oitocentos artigos publicados, foram encontrados cinco artigos sobre o trabalho do pedagogo nos Institutos Federais de Educação.

Os trabalhos relacionados sobre o pedagogo nos IFs são construídos com base em pesquisas na realidade dos institutos, contendo considerações a partir de análises de documentos próprios dos institutos, observações e entrevistas com pessoas partícipes dessa mesma realidade, o que nos dá um panorama significado do trabalho desse profissional. Cada autor ou grupo de autores dos trabalhos encontrados tiveram uma diferente forma de desenvolvimento, porém, todos os conteúdos e os resultados das pesquisas direcionam a interessantes conclusões.

No artigo de Bacheti; Oliveira (2011), publicado na revista Debates em Educação Científica e Tecnológica, fala-se sobre a atuação do pedagogo no Programa de Educação Profissional de Jovens e adultos PROEJA/FIC em cursos do IFES quanto aos aspectos pedagógico. 
A questão do trabalho é "Como os pedagogos que atuam nos cursos do PROEJA constroem sua identidade?". Para realizar essa análise, foram utilizados questionários com 14 perguntas aplicados para 14 docentes com questões pessoais, de relacionamento interpessoal, sobre o programa e sobre o trabalho do pedagogo.

A partir dessa metodologia foi traçado um perfil dos docentes, coletado a percepção deles sobre o programa e levantado os motivos que levam o docente a procurar o pedagogo. Quanto ao que diz respeito à atuação, foi apontada a procura ao pedagogo quanto aos aspectos pedagógicos, subjetivos e operacionais.

No resultado quanto aos aspectos pedagógicos, os docentes disseram que solicitam o pedagogo com questões de planejamento, avaliação, recursos de trabalho, conhecimento dos alunos com ou sem necessidades especiais e capacitações para o trabalho.

Quanto aos aspectos subjetivos, os docentes relataram procurar os pedagogos com questões comportamentais dos alunos, como a indisciplina. Sobre os aspectos operacionais, os professores procuram para tirar dúvidas administrativas como, por exemplo, preenchimento de diários.

Nessa pesquisa, foi registrada a opinião de outros profissionais da instituição que apontaram para a importância do pedagogo na acolhida de alunos ingressantes, assessoramento e organização de processos avaliativos, tendo o papel estratégico de contribuir com a equipe docente.

Nas conclusões desse trabalho, os autores colocam que o pedagogo atua no espaço do IF com os papéis de supervisor escolar, articulador de toda a comunidade escolar, profissional que acompanha alunos e professores, que cuida de aspectos administrativos como o de preenchimento de diários e pagamento de bolsa dos alunos, como mediador e organizador do espaço e tempo escolar.

Já o artigo de Brandt; Nascimento, Magalhães; Silva (2014), publicado na revista Eixo, discute as atribuições, saberes e condições de trabalho do pedagogo na educação profissional do Instituto Federal de Educação Ciência e Tecnologia de Santa Catarina (IFSC) e no Instituto Federal de Educação Ciência e Tecnologia Catarinense (IF Catarinense). A questão principal é "Qual a influência da ação do pedagogo e quais as contribuições na construção de uma educação de qualidade nos IFs de SC?".

Mostra a constatação de que o pedagogo dos IFs tem nas suas atribuições o papel de supervisão com a proposta de organizar e sistematizar os diversos conhecimentos. Acrescenta ainda, que ele precisa acompanhar as atividades educacionais utilizando de amplos saberes de forma a contribuir para a qualidade na educação desse espaço.

Através de questionamentos aos próprios pedagogos sobre suas atribuições, eles relataram sobre a atuação que: quanto ao cotidiano escolar eles planejam, organizam e executam atividades didático-pedagógicas; quanto à assessoria eles realizam acompanhamentos pedagógicos, planejam e realizam projetos, atuam na elaboração de Planos de Curso e orientam os professores quanto aos planos de ensino. Além disso, as pedagogas atuam na organização didático-pedagógica, planejando e organizando reuniões como o conselho de classe, acolhimento de docentes, 
acompanhamento de livros didáticos, atendimento ao público interno e externo em contextos diferentes e na formação docente e discente.

Foi constatado pelos autores que o trabalho do pedagogo influencia no cotidiano docente e discente e que, dessa forma, o pedagogo precisa ser um profissional polivalente em sua prática, fazendo com que ela seja significativa para todos do processo educativo.

O trabalho de Carvalho (2014), publicado na revista HOLOS, teve o objetivo de "possibilitar a compreensão sobre os desafios postos ao trabalho do pedagogo na função de supervisora de uma instituição de educação profissional." No caso, o Instituto Federal de Ciência e Tecnologia do Amapá (IFAP). Ele traz um estudo sobre a formação e papel do pedagogo no Brasil, sobre o espaço da educação profissional, a relação do pedagogo com os professores e os desafios da gestão pedagógica. Para tanto, foram aplicadas entrevistas com professores.

A autora parte da perspectiva de que "o papel do pedagogo como articulador, entre as questões administrativas e didático-pedagógicas, ou seja, como executor de tarefas e saberes fundamentais à prática docente". Assim, professores, de maneira geral, consideraram os pedagogos como parceiros para o bom andamento das atividades educacionais na instituição, com alguns conflitos de opinião.

As pedagogas entrevistadas consideraram que existe uma relação de parceria com os professores, mas, que por parte de algum deles há uma rejeição, advinda da origem da supervisão escolar. E com a gestão, a relação é aberta a diálogos e parceira, ressaltando que a direção também é ocupada por uma pedagoga. Foi relatado também, que a relação entre docentes e pedagogos é bem conflituosa, mas, que as resistências vêm diminuindo.

As pedagogas também relataram que a formação no curso de Pedagogia não proporcionou conhecimento totalmente satisfatório para a atuação no campo da educação profissional, necessitando de estudos posteriores. Em geral, foi relatado que na área de atuação são utilizados os conhecimentos da educação básica, mas é necessário complemento sobre a educação profissional.

O estudo de Brandt e Magalhães (2013), publicado na revista Técnico-Científica, as autoras discutem a partir das atribuições do pedagogo quais são as contribuições do trabalho desse profissional na qualidade da educação profissional e tecnológica. A pesquisa foi realizada nos IFs de Santa Catarina e teve como objetivos "conhecer os fatores que causam a satisfação dos colaboradores; diagnosticar o trabalho do pedagogo desenvolvido nas instituições educacionais pesquisadas e propor alternativas para a melhoria dos serviços prestados." (p.562).

No resultado da pesquisa constatou-se que o serviço prestado pelo pedagogo é regular e que necessita melhorar o assessoramento da supervisão pedagógica e algumas atividades exercidas por pedagogos na supervisão escolar foram consideradas péssimas.

Para as autoras o pedagogo que atua na educação profissional precisa ter conhecimentos sobre a escola, sobre a legislação, sobre o desenvolvimento humano e ser um pesquisador da realidade escolar, sendo capaz de fazer leituras dessa realidade e promover as mudanças necessárias. Dessa maneira, caberia ao pedagogo realizar atividades que possibilitassem a qualidade do ensino. 
O artigo de Gonçalves, Abensur e Queiroz (2009), publicado na revista SINERGIA, apresenta uma discussão sobre a identidade dos profissionais especialistas em educação como pedagogos ou Técnicos em Assuntos Educacionais (TAEs) na Rede Federal de Educação Profissional, Científica e Tecnológica (REFEPT), da qual fazem parte os IFs. Foi realizado por servidores do Instituto Federal de São Paulo compostos por dois pedagogos e uma licenciada em letras, pela formação superior inicial. Eles utilizaram a análise documental.

Foi apontado que tanto o trabalho do cargo de Pedagogo quanto o Cargo de TAE envolvem atividades voltadas à "administração, planejamento, inspeção, supervisão, orientação educacional para a educação básica, que os remete a uma identidade de especialista em educação." (p.10).

Para a contextualização são colocadas as atribuições dos dois cargos, TAE e Pedagogo. A partir daí foi visto que os dois cargos se ocupam de trabalho com natureza pedagógica e exigiam conhecimentos específicos para garantir o desempenho profissional. Foi feita a análise de que, segundo as diretrizes curriculares, os saberes dos arcabouços pedagógicos para essa atuação devem ser encontrados nos cursos de formações de professores e pedagogia e que isso é corroborado pela LDB em seu artigo 61, incluído pela Lei $n=12.014 / 2009$. Os autores colocam que "o especialista em educação é visto como um mediador da educação e aprendizagem de todos que compõem o processo educativo". (p. 12)

Para os autores o fato dos TAEs e pedagogos, especialistas em educação, estarem classificados na carreira de técnicos-administrativos aumenta as desavenças entre desses profissionais técnicos com os docentes, com uma volta ao passado e trazendo prejuízos ao desenvolvimento de uma educação de qualidade.

\section{ANÁLISE DO CENÁRIO SOBRE A ATUAÇÃO DO PEDAGOGO ENCONTRADO NOS TRABALHOS}

Embora a maiorias desses institutos pertença a estados brasileiros diferentes e, portanto, a realidade com diferenças entre si, a atuação dos pedagogos tem vários pontos em comum. Um dos pontos em comum mais relevante e visível é quanto à área de atuação do pedagogo. Assim, as análises apontam que o trabalho do pedagogo está ligado à supervisão escolar e gestão educacional tanto relacionado aos processos didático-pedagógicos quanto aos pedagógicoadministrativos. Todos os autores também apontam que o trabalho do pedagogo engloba a atuação com toda a comunidade escolar: docentes, discentes, técnicos, família, incluindo o público interno e externo, articulando-os, por exemplo, com o mundo do trabalho.

Quanto à relação entre os pedagogos técnicos e os docentes, todos os trabalhos apontam para uma dualidade ou discordância das duas partes, havendo dificuldades nas relações, embora, alguns trabalhos apontem para um caminho de superação. Alguns também apontam que esse desconforto na relação de trabalho advém da construção histórica negativa da supervisão escolar, da qual o pedagogo se ocupa na maioria das vezes nos institutos.

Com certa contradição, em geral os trabalhos dos autores também mostram que há uma grande procura pelos pedagogos por parte dos docentes em diversos momentos do processo educativo, tornando o pedagogo importante na construção de todas as etapas didáticas desenvolvida pelos professores. 
Em todos os trabalhos, fica nítido que os pedagogos precisam mobilizar amplos saberes que envolvem todos os processos escolares e alguns ressaltam que, na prática, a formação superior inicial não supre as demandas do trabalho na educação profissional.

Quanto aos desafios dos pedagogos, podem ser pontuados: a necessidade de buscar formação complementar para atender as demandas; superar a resistência dos outros profissionais e constituir uma atuação de forma polivalente.

\section{CONSIDERAÇÕES FINAIS}

A busca pelo delineamento da identidade do pedagogo que atua nos Institutos Federais passa pelo obstáculo da falta de bibliografia específica sobre o tema. Embora o pedagogo esteja inserido na realidade desses espaços desde a sua criação, ainda há poucos estudos que representem esse espaço de conhecimento.

Sabendo que os espaços educativos, sobretudo os escolares, refletem as transformações sociais e que, por sua vez, esses espaços modificam a sociedade. A formação profissional técnica e tecnológica ofertada pelos IFs é uma demanda social. Esses espaços formam profissionais para atuarem imediatamente no mundo do trabalho. Dessa forma, todo trabalho desenvolvido nos IFs, reflete na realidade social de maneira significativa e rápida, isso torna ainda mais importante que os profissionais dessa área aliem constantemente o engajamento profissional e social.

Os profissionais desses espaços devem, além do conhecimento sobre a sua área específica, buscar conhecimento e comprometimento relacionados à realidade política, econômica e social. Para que o pedagogo possa contribuir efetivamente com processos educativos no espaço dos Institutos Federais, é importante que ele tenha construído em sua concepção profissional qual é o seu real papel e importância nesse espaço. Nesse sentido, trabalhos que contribuam para essa construção de identidade se tornam importantes para ampliar esse conhecimento e tornar mais consciente a atuação do pedagogo.

Acreditamos que explorar esse espaço de atuação do pedagogo, nos IFs, em que ele é um profissional em evidência nas relações escolares, pode contribuir para uma concepção mais valorizada dessa profissão, maior conhecimento sobre as potencialidades de atuação profissional e uma reflexão acerca da formação necessária para atender as demandas complexas para as quais o pedagogo vem sendo solicitado.

\section{REFERÊNCIAS}

1. BACHETI, L. S. P; OLIVEIRA, A. J. Pedagogo no proeja: identidades e saberes. Revista Debates em Educação Científica e Tecnológica, v. 01, n. 1, Espírito Santo, 2011.

2. BACHETI, L. S; FERNANDES, M. A. S; SILVA, M. I. C. Reflexões acerca do papel do pedagogo na educação profissional: articulando os saberes docente e do pedagogo. In: II Seminário Nacional de Educação Profissional e Tecnológica (SENEPT), 2012, Minas Gerais,

3. BRANDT, A. G; NASCIME, F. S. C; MAGALHÃES, N. R. S. As contribuições da prática pedagógica do pedagogo pela qualidade da educação profissional dos IFETs de Santa Catarina - SC. Revista SICT - Sul, Criciúma - SC, v.2 n.2, edição especial de 2013. 
4. BRANDT, A. G; NASCIMENTO, F. S. C; MAGALHÃES, N. R. S; SILVA, M. C. O trabalho do pedagogo nos IFs: uma busca pela qualidade da educação profissional tecnológica. Revista EIXO, Brasília - DF, v.3 n.1, Janeiro - Julho de 2014.

5. BRASIL, Lei no 11.892, de 29 de dezembro de 2008. Institui a rede federal de educação profissional, científica e tecnológica, cria os institutos federais de educação, ciência e tecnologia, e dá outras providências. Disponível em http://www.planalto.gov.br/ccivil_03/_ato2007-2010/2008/lei/l11892.htm

6. BRASIL, Lei, 9.394, 20 de dezembro 1996. Estabelece as Diretrizes e Bases da Educação Nacional. Disponível em http://www.planalto.gov.br/ccivil_03/leis/19394.htm

7. BRZEZINSKI, Iria. Pedagogo: Delineando identidade(s). Revista UFG, n. 10, p. $120-131$, ano XIII.

8. CARVALHO. I. A. Os desafios do pedagogo na função supervisora em uma instituição de educação profissional. Revista HOLOS, Ano 30, v. 2 -2014.

9. CLARO, J. A.C. S; TORRES, M. O. F. pedagogia empresarial: a atuação dos profissionais da educação na gestão de pessoas. Revista Contrapontos - Eletrônica, v. 12 - n. 2. P. 207 - 216.

10. CONSELHO NACIONAL DE EDUCAÇÃO. Institui Diretrizes Curriculares Nacionais para o Curso de Graduação em Pedagogia, Licenciatura. Resolução CNE/CP, nº 1, 15 de Maio de 2006.

11. FRANCO, M. A. S. Entre a lógica da Formação e a Lógica das Práticas: a mediação dos saberes pedagógicos. Revista EDUCAÇÃO E PESQUISA, v. 34, n. 1 São Paulo jan./abr. 2008

12. GOHN, M. G. Educação não formal e educador social atuação no desenvolvimento de projetos sociais. São Paulo: Cortez, 2010.

13. GONÇALVES, H. J. L; ABENSUR, P. L. D; QUEIROZ, S. Q. Identidade de profissionais da educação na rede federal de educação profissional científica e tecnológica: os especialistas em educação. Revista SINERGIA, São Paulo, v.10, n.1, jan./jul. 2009.

14. LIBÂNEO, J. C. Pedagogia e pedagogos, para quê? - Ed. 12. São Paulo: Cortez, 2010.

15. MELO, A. L. B. As práticas educativas desenvolvidas por pedagogos em espaços não escolares e os saberes profissionais mobilizados. In: Seminário ANPAE, Goiás, 2012.

16. MOREIRA. G. A. Entre a formação acadêmica e o exercício profissional: a atuação do pedagogo em espaços não escolares. In: V Encontro De Pesquisa Educacional em Pernambuco (EPEPE), 2014, Pernambuco.

17. ORTEGA, A. C. O pedagogo e a gestão a favor da docência. In: $\mathbf{X}$ congresso nacional de educação, 2011, Paraná.

18. PAULA, E. M. A. T; MACHADO, E. R. Pedagogia: concepções e práticas em transformação. Revista EDUCAR EM REVISTA, n. 35, 2009, Curitiba.

19. PINTO. U. A. Pedagogia escolar Coordenação Pedagógica e Gestão Educacional. São Paulo: Cortez, 2011.

20. SAVIANI, D. O espaço acadêmico da pedagogia no Brasil: perspectiva histórica. Revista PAIDÉIA, n. 28, v. 14, Ribeirão Preto. 2004.

21. SAVIANI, D. O papel do pedagogo como articulador do trabalho pedagógico na sociedade do 
capital. In: Palestra UENP Cornélio Procópio, Paraná, 2012.

22. TRILHA, Jaume; GHANEM, Elie; ARANTES, Valéria Amorim, (org). Educação formal e nãoformal: pontos e contrapontos. São Paulo: Summus, 2008. 